\title{
Facts and values: on the acceptability of risks in children's sport using the example of rugby $-a$ narrative review
}

\author{
Kenneth Lincoln Quarrie, ${ }^{1,2}$ John H M Brooks, ${ }^{3}$ Nicholas Burger, ${ }^{4}$ Patria A Hume, ${ }^{2}$ \\ Steve Jackson ${ }^{5}$
}

\begin{abstract}
${ }^{1}$ New Zealand Rugby, Wellington, New Zealand ${ }^{2}$ Sports Performance Research Institute, Faculty of Health and Environmental Sciences, Auckland University of Technology, Auckland, New Zealand

${ }^{3}$ The Population Health Research Institute, St George's University of London, London, UK ${ }^{4}$ Exercise Science and Sports Medicine, University of Cape Town, Rondebosch, South Africa ${ }^{5}$ School of Physical Education, Sport \& Exercise Sciences, University of Otago, Dunedin, New Zealand
\end{abstract}

\section{Correspondence to}

Dr Kenneth Lincoln Quarrie, New Zealand Rugby, 100 Molesworth Street, Wellington 6140, New Zealand; ken.quarrie@nzrugby.co.nz

Accepted 7 June 2017 Published Online First 22 June 2017

\section{CrossMark}

To cite: Quarrie $\mathrm{KL}$, Brooks JHM, Burger N, et al. Br J Sports Med 2017:51:1134-1139.

\section{ABSTRACT}

A clash of values has been identified between those who assert that:

1. all childhood injuries, regardless of origin, are inherently undesirable and should be prevented and; 2. those who believe that some measure of injury to children is an acceptable compromise for the physical benefits associated with physical activity and the development of abilities to appraise and deal with risks. A debate regarding whether the tackles and collisions permitted in schools' rugby represent acceptable risks, and what steps should be taken if they do not, exemplifies the issue.

Questions regarding the magnitude of injury risks in sport are issues of fact and can be quantified via the results of injury surveillance studies. Risks are neither high nor low in isolation; they are relatively high or low with reference to other activities or across groups participating in an activity. Issues of the acceptability of a given degree of risk are value dependent. Research regarding perceptions of risk reveals wide variations in the degree of risk people view as acceptable. Factors impacting on risk perception include whether the risks are well known and understood, whether they are 'dread' risks and the degree to which people undertake the risks voluntarily and feel they have control over them.

Based on the evidence currently available, the risks to children playing rugby do not appear to be inordinately high compared with those in a range of other childhood sports and activities, but better comparative information is urgently needed. Further evidence, however, should not necessarily be expected to result in the resolution of acceptable risk debates-pre-existing values shape our perspectives on whether new evidence is relevant, valid and reliable.

\section{INTRODUCTION}

On 1 March 2016, the 'Sport Collision Injury Collective', a group of 73 'academic researchers and healthcare professionals' led by Professors Allyson Pollock and Eric Anderson sent an open letter to Chief Medical Officers, Children's Commissioners, Government Ministers, and Education Officers in the UK and Northern Ireland. ${ }^{1}$ The letter called for the removal of 'the tackle and other forms of harmful contact' from school rugby, on the basis that the injury risks involved in the sports of rugby union and rugby league are unacceptably high. The letter prompted significant debate in the media, ${ }^{2}$ ${ }^{3}$ and Tucker et al, in a response published in the
BJSM, claimed that a 'complete ban on tackles is unnecessary and may be detrimental. ${ }^{4}$

Pollock is a professor of public health research and policy, and in her 2014 book Tackling Rugby: What every parent should know about injuries ${ }^{5}$ has provided a great deal of detail about why she believes a ban on contact should be implemented in schools' rugby. In her book, she stated:

Rugby is a high-impact collision sport that entails an expectation of some injuries. At what point do injuries become sufficiently serious and sufficiently frequent to be unacceptable? $?^{5}$

The question raised is a good one and applies to all sports and recreational activities for all ages, not just rugby. The purposes of this manuscript are to:

1. discuss how values can shape whether a given risk is viewed as acceptable or unacceptable; and

2. describe the risks in youth rugby.

\section{Approaches to acceptable risk}

Questions regarding the magnitude of injury risks in sport are questions of fact and can be addressed directly via the results of injury surveillance studies. Risks are neither high nor low in isolation; they are relatively high or low with reference to the risks involved in other activities, or across specified groups participating in the same activity (eg, rugby players at different grades of play or occupying different positional roles). Evaluations of the acceptability of risks are, to a greater extent, value dependent. 6 According to Fischhoff et al, because there is no 'all-purpose' number that expresses acceptable risk, the best people can hope for is to 'find the most acceptable alternative in a specific problem, one that will represent the values of a specific constituency'. ${ }^{6}$

\section{A clash of values in sports injury prevention?}

Participation in sport and vigorous physical activity confers a range of physical and psychological health benefits. ${ }^{78}$ These benefits are offset to some extent by the injuries sustained during and morbidity associated with playing sport or exercising, which raises issues about the extent to which injuries sustained during participation in sports might be considered 'acceptable'. ${ }^{8-10}$

Molcho and Pickett, ${ }^{10}$ in a 2011 opinion paper, identified a clash of values underpinning the prevention of childhood injuries when they claimed that injury prevention specialists 'typically offer the perspective that childhood injuries are inherently 
bad, irrespective of their origins', whereas those involved in promoting health through physical activity 'often argue that injury is an inevitable side effect of a healthy, active lifestyle'. The issue was encapsulated as follows:

Should society be aiming to prevent all minor injuries to children at the cost of limiting engagement in physical activity? Is our profession's basic mantra that 'all injuries are predictable and hence preventable' inadvertently causing harm? Has the time come for the injury prevention world to view certain childhood injury events in a different light, perhaps accepting that there is a threshold incidence for childhood physical activity injuries below which it might be difficult or even not sensible to concentrate our prevention efforts? ${ }^{10}$

Molcho and Pickett proposed that injuries in which any of the following applied would be deemed 'unacceptable': intentional, severe/fatal or disabling, occurring in activity that was unnecessary and/or risk generating, via a mechanism that was dangerous, or where preventive measures had not been adhered to. ${ }^{10}$ The proposal generated considerable discussion, ${ }^{11-14}$ with one commentator raising the question of 'whose norms?' applied (eg, with respect to whether the activity is 'necessary and health generating') ${ }^{14}$ and others identifying that operationalising the criteria would be problematic; for example, 'what measures and thresholds would we use to decide whether the activity was necessary and did not have long term consequences? ${ }^{? 11}$ Langley and Cryer held that we should seek to understand which activities were associated with severe injuries and carry the greatest costs to society, and focus our prevention efforts on those. ${ }^{11}$

In the current debate, Pollock has stated:

School rugby should be made safe. We know that most injuries occur as a result of contact, so there is already a strong case for restricting or abolishing the contact element of the game... if it turns out that rugby cannot be played safely, and those proponents of the game are unwilling to confront the truth about contact being the cause of injury, then the case for a ban would be made. Our starting point must be the safety and well-being of our children. First do no harm. ${ }^{5}$

Pollock's statements here are consistent with what Molcho and Pickett referred to as the 'dominant paradigm' among those working in childhood injury prevention that 'all childhood injuries, irrespective of origin, are unacceptable'. The statements made in Pollock's book, in the open letter, and those she has made in media articles, raise the question of what level of injury to children resulting from participation in rugby would be seen by her and the signatories of the open letter as 'acceptable', or even 'tolerable'. If the answer is 'none', there is no debate to have. It follows that if no injuries to children are acceptable, contact rugby for children should be banned, with similar logic presumably resulting in bans for other activities that carry risks of injury and/or death to children such as football, gymnastics, cycling/mountain biking, fairground rides, swimming, climbing trees, hiking, rock climbing, snow sports, sailing, fishing, equestrian and being transported to and from school by car or motorcycle.

In a liberal democracy, people are free, to a large degree, to hold and express whatever opinions they wish. The values of the signatories of the open letter, most of whom are scholars of sociology, rather than injury prevention or public health, are relevant to what level of risk they believe is acceptable in rugby. ${ }^{15}$ For example, a co-signatory of the open letter asserted in a research article he co-authored that, with respect to rugby, 'participation influences men to exhibit, value and reproduce orthodox notions of masculinity'. ${ }^{16}$ In that paper, he is described as being 'contemptuous of men's team sports'. ${ }^{16}$ While having concern for the health of children and wishing to keep them safe from harm is obviously not mutually exclusive to a dislike of rugby based on other reasons, the point made by Fischhoff $e t a l^{6}$ regarding the importance of attempting to separate issues of fact from issues of value in acceptable risk debates is worth keeping in mind. The extent to which the call for the ban on contact in schools' rugby is predicated on concern for player welfare due to the injuries that result from rugby, versus antipathy for the values, hegemony and 'privileges' that rugby is believed to promulgate is unclear from the letter. If reasons other than those concerning player welfare were a motive for the authors of the open letter calling for a ban on contact in schools' rugby, then stating those reasons in the letter would have helped clarify the debate.

Injury prevention as a field of academic enquiry is grounded in the social sciences, and leading practitioners have identified that it is not a 'value-free' activity. Those involved are typically starting from the position that injuries are a societal harm that should be reduced or eliminated. ${ }^{9}{ }^{17}$ Bonnie and Guye, when outlining the achievements and challenges facing injury prevention as field of scientific study commented that it was 'important for investigators to avoid becoming so invested in a particular policy position that they compromise public confidence in the objectivity and integrity of the scientific process' ${ }^{17}$ Finding ways to balance the demands of science and advocacy was identified as 'one of the ongoing challenges for the injury field, as elsewhere in public health'. ${ }^{17}$ Questions about whether this balance has been achieved with respect to the current debate have been the subject of previous correspondence. ${ }^{18}$

\section{What factors underpin our perceptions of whether risks are acceptable?}

Slovic, in a paper on risk perception published in 1987, identified a range of psychological factors that influence how people perceive risk, and whether they view a given risk as acceptable. ${ }^{19}$ These include whether the risks are well known and understood, whether they are 'dread' risks and the degree to which people undertake the risks voluntarily and feel they have control over them. ${ }^{19}$ Starr concluded that the public were likely to accept risks from 'voluntary' activities that were roughly 1000 times higher than those that were a result of 'involuntary' activities. ${ }^{20}$

In sport, Fuller and Ward ${ }^{21}$ conducted a survey in which they queried groups of rugby players and spectators about their views on the acceptability of different rates and severity of injury. They found that, even within the groups, there existed wide variations in the level of risk that was believed to be acceptable. ${ }^{21}$ This may be due in part to the range of sources that contribute to the perception of risk, including scientific data, expert comments, media reports, peer group views and personal observations. ${ }^{22}$ In addition, the degree to which we like a given activity appears to influence the amount of risk we are willing to tolerate in that activity. It would therefore be unsurprising if those who participated in and promoted rugby were prepared to countenance a higher rate of injuries as being 'acceptable' than those who disliked the sport.

Substantial research supports the view that our values influence the facts we view as relevant and the weight we give themsomething that applies to many areas in which judgements are made under conditions of uncertainty. ${ }^{23}$ Therefore, it is difficult for people, even scientists, to separate facts from values. Fischhoff $e$ t al stated: 'Beliefs about the facts of the matter shape our values; in turn, those values shape the facts we search for and how we interpret what we find ${ }^{6}{ }^{6}$ Slovic made similar points: 'New evidence appears reliable and informative if it is consistent 
with one's initial beliefs; contrary evidence tends to be dismissed as unreliable, erroneous, or unrepresentative'. ${ }^{19}$

\section{Do 'dangerous sports' have benefits that offset the injury risks and costs? \\ If you look too closely at the game it's silly really when you bash the hell out of each other. But it's fun and if you took the risk out of everything you wouldn't do anything in your life.}

Richie McCaw, former All Blacks captain, $2017^{24}$

Scholars of sports philosophy have considered the phenomenon of 'dangerous' sports and developed arguments both for and against the legitimacy and value of them. These have included deontological perspectives as well as utilitarian arguments regarding the extent to which personal autonomy to take risks needs to be balanced by societal regulation.

Professor John Russell held that 'physical risk or danger does contribute some important value, albeit indirectly, to a child's good'. Russell defined a dangerous sport as 'one that involves activity that itself creates a significant risk of loss of, or serious impairment to, some basic capacity for human functioning. ${ }^{25} 26$ Russell articulated two main arguments for the value of dangerous sports. The first argument posits that 'physical risk is essential to the healthy development of a variety of important physical virtues' and that removing all risks from a child's environment would leave them unprepared to confront physical risks and unable to make sound judgements about risks in their adult lives. A systematic review of the effect of risky outdoor play provides qualified support for Russell's view. Risky outdoor play was found to be related to a range of positive physical health and social outcomes for children when compared with 'non-risky' play. ${ }^{27}$

The second argument raised by Russell, which he acknowledged was a more controversial position, asserts that a degree of risk above that which is necessary for the development of skills in appraising and dealing with risks should often be tolerated in children's sport because of the value of 'self-affirmation' that can result from being tested to one's physical limits in the presence of high levels of risk. Russell believes testing one's perceived limits in the presence of danger is a fundamental part of childhood, a means 'of creating and affirming and thus discovering who and what they are'. Russell holds the view that the wishes of the child and parents should be strong considerations in whether any particular 'dangerous' activity is suitable for, or acceptable to, the child. ${ }^{26}$

\section{What is known about the injury risks of rugby to children and youth?}

To date, there have been two systematic reviews of rugby injuries (in general, as opposed to reviews of specific types of injury) to children and youth. ${ }^{28}{ }^{29}$ Bleakley and colleagues ${ }^{28}$ reviewed 15 studies of rugby injuries to players aged 12-18 years in 2011. The authors observed that a wide range of injury definitions and data collection methods had been used, that injury rates among adolescent players tended to increase with age, that the tackle was consistently the most common cause of injuries and that rates of injury among adolescent players appear to be systematically lower than among adults.

In 2015, Freitag et al published a systematic review of 35 studies of rugby injury to players under the age of 21 years. ${ }^{29} \mathrm{~A}$ feature of the review was the large degree of interstudy heterogeneity that was found to exist. The $95 \%$ prediction interval, which is 'a $95 \%$ range for the incidence rate that might underlie the observed rate in any given study, taking account of the heterogeneity between studies' was 1.7 to 433 injuries per 1000 player-hours for studies in which injuries were recorded 'irrespective of need for medical attention or time away from play'. In her book, ${ }^{5}$ Pollock concluded:

Ultimately then, our review of worldwide epidemiological studies into the incidence of injury from youth rugby union shows no consistency in reported rates. There is almost a nineteen-fold difference between the highest and lowest reported incidence of injury, with the highest rate at 130 injuries per 1000 player-hours and the lowest at seven injuries per 1000 player-hours.

The implication of this statement is that the true risk of injury among school-aged rugby players was yet to be well established. Even so, Pollock et al stated in the open letter that 'Studies show that the risks of injuries for those aged under 18 years are high and often serious ${ }^{11}$ and has claimed elsewhere that the "high risks and rates of injury in rugby are well established and consistent across many studies throughout the world of injury in rugby'. ${ }^{30}$

Freitag et $a l^{29}$ drew attention to several limitations that might impact on the interpretation of the analysis they presented. These included interstudy differences in injury definition, issues with respect to who captured the data and whether injuries from matches and training sessions were grouped or reported separately. A limitation that the authors did not point out was the age of the studies from which the estimates of pooled injury incidence were drawn. ${ }^{29}$ The pooled incidence figure of 26.7 injuries per 1000 player-hours (95\% CI 13.2 to 54.1) appears to have been based on five studies, of which the data from two were collected primarily in the 1970s, two in the 1990s and one in the early 2000 s.

Two studies published since the review by Freitag et al ${ }^{29}$ have reported similar match injury incidence for youth rugby players-29 and 24 injuries per 1000 player-hours respectively. ${ }^{31} 32$ If we assume the 'pooled incidence rate' and corresponding probabilities of injury reported by Freitag et $a l^{29}$ fairly reflect the rates and risks of injury typically experienced by school-aged players playing rugby in the present day, do they represent high risks?

The reported rates as presented by Freitag et al, and converted to 'exposures per injury' statistics, are presented in table $1 .^{29}$ Based on the exposure estimate used by Freitag et al, a youth player facing a probability of $12 \%$ per season of sustaining an injury that requires a week or more away from play can expect to be injured once every 117 matches, or once every eight seasons of play. ${ }^{29}$ We imagine there would be a wide range of opinions about whether an activity that results in a person being injured to the extent they cannot play for a week or more once

Table 1 Injury risks for children's rugby presented using injuries per unit of time, probability per season and time to injury based on Freitag et al ${ }^{29}$

\begin{tabular}{|c|c|c|c|c|}
\hline Injury severity & Injury rate per 1000 player-hours & $\begin{array}{l}\text { Probability of injury per season } \\
(15 \times 50 \text { min matches })\end{array}$ & Matches per injury & Seasons per injury \\
\hline Any injury & $26.7(13.2-54.1)$ & $28.4 \%(15.2 \%-49.1 \%) \%)$ & $45(95 \% \mathrm{Cl} 22$ to 91$)$ & $3(95 \% \mathrm{Cl} 1$ to 6$)$ \\
\hline$\geq 7$-day absence & $10.3(6.0-17.7)$ & $12 \%(7.2 \%-19.8 \%) \%)$ & $117(95 \% \mathrm{Cl} 68$ to 200$)$ & $8(95 \% \mathrm{Cl} 5$ to 13$)$ \\
\hline
\end{tabular}


every eight seasons of play represents an 'unacceptably high' risk.

\section{Risks associated with the contact elements of rugby}

Notwithstanding the variability in injury rates reported by different studies, the tackle has consistently been identified as the element of rugby associated with the greatest 'injury burden' (the product of injury incidence and severity). ${ }^{33}$ This finding appears to be robust across age groups and is related to the fact that tackles are both a frequent occurrence during matches and often involve relatively large (in a sporting context) energy transfers among players, or between players and the playing surface.

Preliminary work on relationships between tackle technique, tackle effectiveness and injury risk in children has been undertaken by Burger et $a l^{3435}$ and Hendricks et al ${ }^{36-39}$ These authors found that tackle technique was related to injury risk; players who displayed worse tackle technique, based on a range of scored characteristics of tackle proficiency, were more likely to sustain an injury during the tackle. The implication of this work is that teaching players 'good' tackle technique is a potential injury prevention strategy.

\section{Risks in youth rugby compared with other sports}

The evidence base for inter-sport comparisons of injury risk is not particularly robust. In a systematic review of childhood injuries across a number of sports, Spinks and McClure noted that inter-study variations in injury definitions, data collection methods and reporting methods resulted in large differences in reported rates that 'did not necessarily represent actual differences in injury risk between activities'. ${ }^{40}$ Match injury statistics from the paper by Spinks and McClure ${ }^{40}$ for those sports that had reported rates per 1000 player hours are shown in figure 1. Each dot on the figure represents a rate reported in a study.

Pollock, in her book, ${ }^{5}$ referred to the work of Spinks and McClure and commented that the work showed that rugby and ice hockey were the most injury-prone team sports for children under the age of 16 years. The information provided in figure 1 raises the question of the basis on which that conclusion was drawn with respect to rugby, the acknowledged limitations of the data notwithstanding.

Collins et $a l,{ }^{41}$ who studied the injury epidemiology of high school rugby players in the USA, also mentioned that caution was needed when comparing across studies and that high school rugby as played in the USA appeared to have a similar injury rate to American football and wrestling, a lower rate than ice hockey and a higher rate than basketball or soccer. Bleakley et $a l^{28}$ reported that rugby was associated with higher rates of injury overall than soccer, basketball or gridiron (American football). They also stated that, based on the available evidence, the prevalence of severe injuries in rugby appeared to be lower than, or was comparable with, those in high school gridiron, soccer and wrestling.

Studies have shown the injury rate among child and youth rugby players is much lower than that experienced by professional players. ${ }^{29} 42$ It may be, however, that because professional rugby is much more heavily publicised than youth rugby via television and print media, the availability heuristic ${ }^{23}$ leads most people to bring to mind the physicality of, and injuries sustained in, professional rugby when they think about risks in rugby, which they then mentally transfer to their perceptions of risks at other levels of the sport.

There is as yet no consensus about what rates of injury of a given severity in sport correspond to low, moderate or high risks. Within the limits of the existing evidence, it does not appear that rugby places children at inordinate risk compared with other sports and activities in which children participate, but clearly better research comparing injury risks and rates across children's and youth sports is needed.

\section{Serious injuries}

Even if the overall frequency of injury in an activity was considered to be commensurate with that of other activities, special concern might be given to 'serious' injuries, especially those that have the potential to result in long-term or permanent disablement or death. Fuller examined the risks of catastrophic injuries in rugby for players aged 13 years and over. ${ }^{43}$ Players aged under

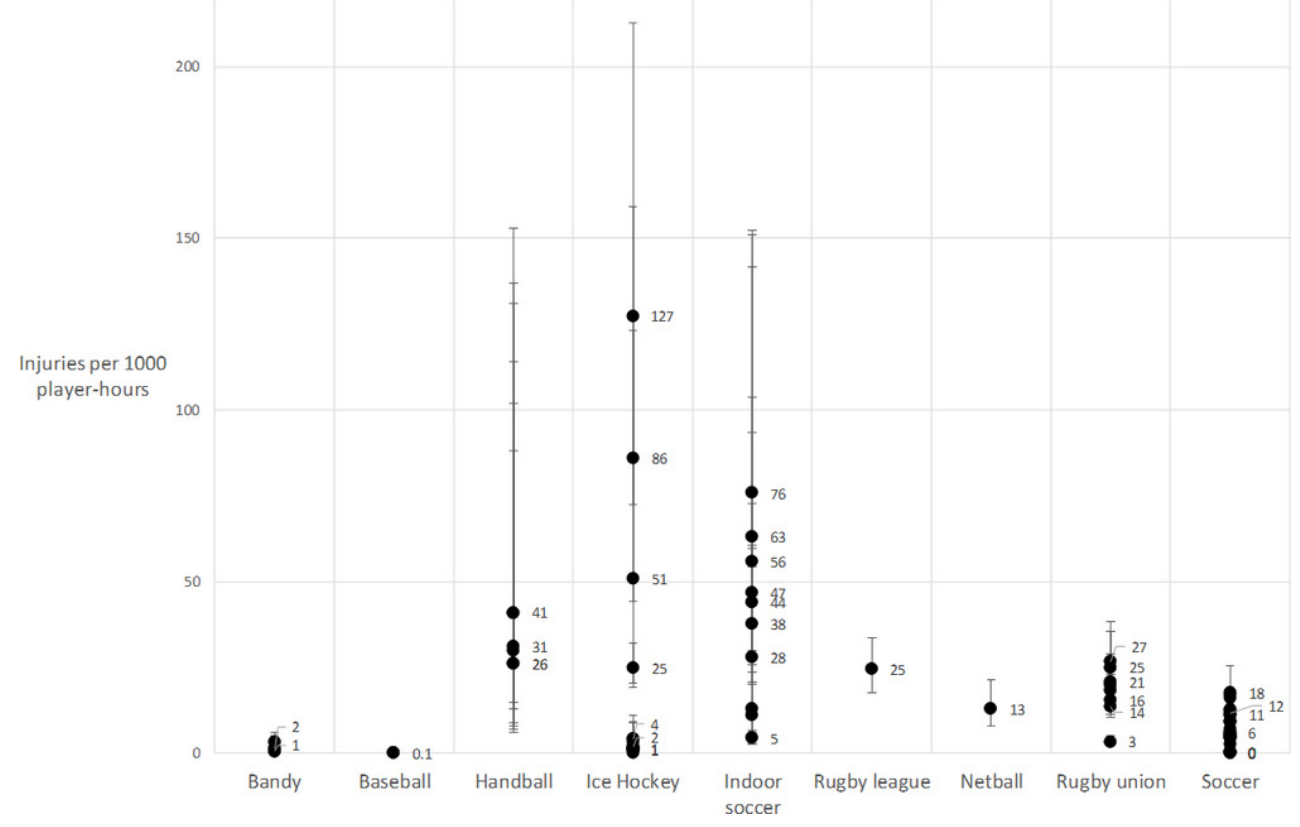

Figure 1 Match injury rates for children's sports (data from Spinks and McClure,table 1). ${ }^{40}$ 
13 years were excluded on the basis that no catastrophic injuries to players of that age had been recorded. Fuller found that, on a per 100000 persons per year basis, the risks were similar to, or lower than, those of other collision sports such as ice hockey, rugby league and American football, and also lower than those experienced by motor cyclists, pedestrians and car occupants. ${ }^{43}$ The comparison with the latter three groups, however, is complicated by the amount of exposure that is typical for those playing rugby being much lower on a per person basis than it is for people involved in transport. Fuller concluded that the risks of catastrophic injury in rugby could thus be considered 'acceptable' based on most of the reported rates and 'tolerable' for the studies that had reported the highest rates. ${ }^{43}$

The rate of rugby-related spinal injuries resulting in permanent disability in New Zealand was reported to be 1.3 per 100000 players per year for the period 2001-2005 across all age groups. This rate represented a substantial drop on that recorded in previous periods and coincided with the introduction of a nationwide injury prevention programme. ${ }^{44}$ No fatalities or permanently disabling spinal or brain injuries have been recorded to players under the age of 15 in New Zealand since 1976. Thus, permanently disabling rugby injuries to children are very rare events. Nonetheless, when they do occur, they have devastating effects on the individual, family and community involved and are rightly termed 'catastrophic'. Following the suggestion of Langley and Cryer that injury prevention efforts should have as their focus 'serious' or severe injuries, ${ }^{11}$ it is beholden on rugby stakeholders to take all reasonable steps to eliminate such injuries from the sport.

\section{Concussion and long-term neurological sequelae}

Concussion has, over the past two decades, emerged as a significant concern for all collision sports. Kirkwood et $a l^{45}$ conducted a systematic review of concussion in youth rugby union and rugby league. As was the case with injuries in general, there existed significant heterogeneity across studies, to the extent that no meta-analysis of the results was possible. The true rate of concussion among children playing rugby is yet to be properly quantified; issues with under-reporting of the injury by players, variations in operational definitions of concussion ${ }^{46}$ and consistency of recording injuries have all contributed to the uncertainty. Nevertheless, the available evidence indicates that youth rugby players are at relatively high risk of concussion compared with youths participating in non-contact sports and non-collision contact sports. Pfister et al, in a systematic review published in 2016 , reported that youth rugby had a higher rate of concussion than ice hockey or American football. ${ }^{47}$ Kirkwood et al reported that in the largest study to date, conducted by McIntosh et $a l{ }^{48}$ the concussion injury rate was 6.9 concussions per 1000 player-hours (95\% CI 4.4 to 9.4 ), which is similar to the rate of 6.0 per 1000 play-hours reported by Archbold et al in Ulster schoolboys in a 2017 paper. ${ }^{31}$ Based on the rate reported by McIntosh et al, and using the season exposure estimate of 15 matches of 50 min duration used by Freitag et al, ${ }^{29}$ each youth player could expect to sustain a concussion once every 11.6 seasons of play (95\% CI 8.5 to 18.2 ).

With respect to whether concussions result in enduring problems for children, a systematic review of psychiatric, psychological and behavioural outcomes following mild traumatic brain injuries (mTBI) by Emery et al in 2016 found 'little evidence to suggest that psychological, behavioural, and/or psychiatric problems persist beyond the acute and subacute period following a mild traumatic brain injury in children and adolescents' ${ }^{49}$
The relationship between participation in collision sports, sports concussion and long-term neurological outcomes, such as chronic traumatic encephalopathy (CTE), Alzheimer's disease and other forms of dementia, is not clear. ${ }^{50}$ Maroon et al, ${ }^{51}$ who conducted a systematic review of the existing case reports of sports-related CTE, found that beyond a history of reported mTBI, no consistent risk factors have been identified that predispose individuals to CTE. Maroon et al concluded that no credible data existed with which to establish the incidence or prevalence of CTE in former contact sports participants. ${ }^{51}$

CTE can currently only be diagnosed postmortem; case reports of autopsies of the brains of American footballers, rugby players and soccer players who displayed dementia-like symptoms have revealed CTE in most, but not all, former players. ${ }^{52-54}$ The contribution of other factors that may play a role in the development of CTE, such as genetics, pre-existing psychological conditions, alcohol and recreational drug use, the use of prescription medications such as opiates and non-steroidal anti-inflammatories to manage pain and anabolic agents is yet to be determined. ${ }^{505355}$ Large-scale epidemiological studies are urgently needed to ascertain the relative risk of dementia (and overall morbidity) among former collision-sport participants compared with similar individuals who did not play collision sports.

\section{CONCLUSIONS}

Finding a balance between advocacy and science is recognised as being an ongoing challenge for those who work in health promotion and injury prevention. ${ }^{17}$ The debate on whether the collisions permitted in rugby, and the injuries that can result, represent an 'acceptable risk' to children highlights a fundamental difference in values between those charged with administering and promoting rugby union as a sport and those who are calling for 'tackles and other forms of harmful contact' to be banned from schools' rugby in the UK.

Based on a review of the evidence, it appears that while better comparative information about the risks of children's sports is urgently needed, claims that rugby places children at inordinate risks with respect to other sports and activities of daily living are currently unsupported. Further evidence, however, should not necessarily be expected to result in the resolution of acceptable risk debates-pre-existing values shape our perspectives on whether new evidence is relevant, valid and reliable. Regardless of their personal views on issues, it is incumbent on scientists to follow the ethical principles that underpin their profession and provide advice on risk management and injury prevention that is based on a dispassionate assessment of all of the relevant evidence that is available. ${ }^{17}$

\section{What are the new findings?}

A debate about whether tackles and other forms of contact should be banned in schools' rugby has highlighted a clash of values in the field of injury prevention.

- Views on acceptability of risks vary widely both within and across stakeholder groups and are strongly influenced by pre-existing beliefs.

- Claims that rugby places children and youths at inordinate risk compared with other sports and activities of daily living are currently unsupported by the research evidence.

- Better comparative information regarding the risks in children's sport and about the long-term health effects of participation in collision sports is urgently needed. 
Contributors KLQ developed the original idea for the content of the paper and led the drafting of the manuscript. All other authors assisted with drafting and editing the manuscript to a degree to warrant authorship based on the guidelines in the Uniform Requirements for Biomedical Research.

Competing interests Dr. Ken Quarrie is employed by New Zealand Rugby, in the role of Senior Scientist; is a member of World Rugby's Medical, Science and Research Working Group, a member of World Rugby's Scientific Committee, and a member of World Rugby's Scrum Steering Group. He is aware of, and complies with, the professional standards expected of scientists as stated in the Royal Society of New Zealand's Code of Professional Standards in Ethics in Science, Technology and the Humanities. Professor Patria Hume specialises in sports injury prevention research, specifically sports injury biomechanics, sports injury epidemiology and sports kinanthropometry. She is aware of, and complies with, the professional standards expected of scientists stated in the Royal Society of New Zealand's Code of Professional Standards in Ethics in Science, Technology and the Humanities. She was commissioned by World Rugby and New Zealand Rugby to lead the WR/ NZR/AUT Rugby Health study in New Zealand, for which AUT received financial contribution towards her salary and other co-researchers' salaries and study costs. Professor Hume was a co-supervisor for Ken Quarrie's PhD. Mr Nicholas Burger is a doctoral student at the University of Cape Town (UCT) specialising in the field of tackle-relatedinjury epidemiology and tackle performance in youth rugby union players. He has previously worked as a researcher for the South African Rugby Union (SA Rugby) and the BokSmart National Rugby Safety Programme, and was granted access to the SA Rugby injury and video databases for use in his thesis. He attests that his research is in accordance with the guidelines and SOPs established by the UCT Human Research Ethics Committee and all his studies have received ethical approval Dr John Brooks was formerly employed by the Rugby Football Union as a researcher examining the epidemiology of rugby among professional players in the United Kingdom. He is currently practicing medicine. Dr Steve Jackson has no relevant conflicts of interest.

Provenance and peer review Not commissioned; externally peer reviewed.

(c) Article author(s) (or their employer(s) unless otherwise stated in the text of the article) 2017. All rights reserved. No commercial use is permitted unless otherwise expressly granted.

\section{REFERENCES}

1 Pollock A, Anderson E. Open letter: preventing injuries in children playing school rugby. 2016

2 UK health experts call for ban on tackling in school rugby. The Guardian, 2016.

3 Kelleher W. World Rugby condemn calls for tackling to be banned at british and irish schools citing the 'positive benefits' for all ages. Daily Mail 2016.

4 Tucker R, Raftery M, Verhagen E. Injury risk and a tackle ban in youth Rugby Union: reviewing the evidence and searching for targeted, effective interventions. A critical review. Br J Sports Med 2016;50:921-5.

5 Pollock A. Tackling Rugby: What Every Parent Should Know. 6 Meard Street, London W1F OEG: Verso Books, 2014

6 Fischhoff B, Lichtenstein S, Slovic P, et al. Acceptable Risk: Cambridge University Press, 1981.

7 Blair SN, Morris JN. Healthy heart-and the universal benefits of being physically active: physical activity and health. Ann Epidemiol 2009;19:253-6.

8 MacDonald J, Myer GD. 'Don't let kids play football': a killer idea. Br J Sports Med 2016:(E pub ahead of print).

9 Bullingham R, White A, Batten J. Response to: 'Don't let kids play football': a killer idea. Br J Sports Med 2017:bjsports-2016-097371 (E pub ahead of print).

10 Molcho M, Pickett W. Some thoughts about 'acceptable' and 'non-acceptable' childhood injuries. Inj Prev 2011;17:147-8.

11 Langley J, Cryer C. A consideration of severity is sufficient to focus our prevention efforts. Inj Prev 2012;18:73-4.

12 Langley JD, Cryer C. On preventing all injuries: a response to pless. Inj Prev 2013;19:151-2.

13 Pless IB. On preventing all injuries. Inj Prev 2012;18:285-6.

14 Rivara F. Counterpoint: minor injuries may not be all that minor. Inj Prev 2011;17:149-50.

15 Anderson ED. The maintenance of masculinity among the stakeholders of sport. Sport Management Review 2009;12:3-14.

16 Anderson ED, MCGuire R. Inclusive masculinity theory and the gendered politics of men's rugby. J Gend Stud 2010;19:249-61.

17 Bonnie RJ, Guyer B. Injury as a field of public health: achievements and controversies. J Law Med Ethics 2002;30:267-80.

18 Quarrie KL. Crying wolf: When media reports distort research evidence. Khan K, ed. $\mathrm{Br}$ J Sports Med Blog: BMJ, 2010.

19 Slovic P. Perception of risk. Science 1987;236:280-5.

20 Starr C. Social benefit versus technological risk. Science 1969;165:1232-8.

21 Fuller CW, Ward CJ. An empirical approach for defining acceptable levels of risk: a case study in team sports. Inj Prev 2008;14:256-61.

22 Fuller CW, Myerscough FE. Stakeholder perceptions of risk in motor sport. J Safety Res 2001;32:345-58.
23 Tversky A, Kahneman D. Judgment under uncertainty: heuristics and biases. Science 1974:185:1124-31.

24 Peters S. Former All Blacks captain Richie McCaw backs World Rugby's new tackle directives despite recent criticism from Billy Vunipola, 2017.

25 Russell JS. The value of dangerous sport. Journal of the Philosophy of Sport 2005:32:1-19.

26 Russell JS. Children and dangerous sport and recreation. Journal of the Philosophy of Sport 2007:34:176-93.

27 Brussoni M, Gibbons R, Gray C, et al. What is the relationship between risky outdoor play and health in children? A systematic review. Int J Environ Res Public Health 2015;12:6423-54.

28 Bleakley C, Tully M, O'Connor S. Epidemiology of adolescent rugby injuries: a systematic review. J Athl Train 2011;46:555-65.

29 Freitag A, Kirkwood G, Scharer S, et al. Systematic review of rugby injuries in children and adolescents under 21 years. Br I Sports Med 2015;49:511-9.

30 Pollock AM, Kirkwood G. Removing contact from school rugby will not turn children into couch potatoes. Br J Sports Med 2016;50:963-4.

31 Archbold HA, Rankin AT, Webb M, et al. RISUS study: rugby injury surveillance in ulster schools. Br J Sports Med 2017;51:600-6.

32 Leung FT, Franettovich Smith MM, Brown M, et al. Epidemiology of injuries in Australian school level rugby union. J Sci Med Sport 2017:740-4.

33 Fuller CW, Brooks JH, Cancea RJ, et al. Contact events in rugby union and their propensity to cause injury. Br I Sports Med 2007;41:862-7.

34 Burger $\mathrm{N}$, Lambert Ml, Viljoen W, et al. Tackle-related injury rates and nature of injuries in South African Youth Week tournament rugby union players (under-13 to under-18): an observational cohort study. BMJ Open 2014;4:e005556.

35 Burger N, Lambert MI, Viljoen W, et al. Tackle technique and tackle-related injuries in high-level South African Rugby Union under-18 players: real-match video analysis. $\mathrm{Br} J$ Sports Med 2016;50:932-8.

36 Hendricks S, Karpul D, Lambert M. Momentum and kinetic energy before the tackle in rugby union. J Sports Sci Med 2014;13:557-63.

37 Hendricks S, Karpul D, Nicolls F, et al. Velocity and acceleration before contact in the tackle during rugby union matches. J Sports Sci 2012;30:1215-24.

38 Hendricks S, Matthews B, Roode B, et al. Tackler characteristics associated with tackle performance in rugby union. Eur I Sport Sci 2014;14:753-62.

39 Hendricks $S, O^{\prime}$ Connor $S$, Lambert $M$, et al. Video analysis of concussion injury mechanism in under-18 Rugby. BMJ Open Sport Exerc Med 2016;2:e000053.

40 Spinks AB, McClure RJ. Quantifying the risk of sports injury: a systematic review of activity-specific rates for children under 16 years of age. Br J Sports Med 2007:41:548-57

41 Collins CL, Micheli LJ, Yard EE, et al. Injuries sustained by high school rugby players in the United States, 2005-2006. Arch Pediatr Adolesc Med 2008;162:49-54.

42 Williams S, Trewartha G, Kemp S, et al. A meta-analysis of injuries in senior men's professional Rugby Union. Sports Med 2013;43:1043-55.

43 Fuller CW. Catastrophic injury in rugby union: is the level of risk acceptable? Sports Med 2008;38:975-86.

44 Quarrie KL, Gianotti SM, Hopkins WG, et al. Effect of nationwide injury prevention programme on serious spinal injuries in New Zealand rugby union: ecological study. BMJ 2007:334:1150.

45 Kirkwood G, Parekh N, Ofori-Asenso R, et al. Concussion in youth rugby union and rugby league: a systematic review. Br J Sports Med 2015;49:506-10.

46 Quarrie KL, Murphy IR. Towards an operational definition of sports concussion: identifying a limitation in the 2012 Zurich consensus statement and suggesting solutions. Br J Sports Med 2014;48:1589-91.

47 Pfister T, Pfister K, Hagel B, et al. The incidence of concussion in youth sports: a systematic review and meta-analysis. Br J Sports Med 2016;50:292-7.

48 McIntosh AS, McCrory P, Finch CF, et al. Head, face and neck injury in youth rugby: incidence and risk factors. Br J Sports Med 2010;44:188-93.

49 Emery CA, Barlow KM, Brooks BL, et al. A systematic review of psychiatric, psychological, and Behavioural Outcomes following Mild traumatic brain Injury in Children and Adolescents. Can J Psychiatry 2016;61:259-69.

50 Carson A. Concussion, dementia and CTE: are we getting it very wrong? J Neurol Neurosurg Psychiatry, 2017; 88: 462-64.

51 Maroon JC, Winkelman R, Bost J, et al. Chronic traumatic encephalopathy in contact sports: a systematic review of all reported pathological cases. PLoS One 2015; 10:e0117338.

52 McKee AC, Cantu RC, Nowinski CJ, et al. Chronic traumatic encephalopathy in Athletes: progressive tauopathy after repetitive head injury. I Neuropathol Exp Neurol 2009;68:709-35.

53 Stein TD, Alvarez VE, McKee AC. Chronic traumatic encephalopathy: a spectrum of neuropathological changes following repetitive brain trauma in Athletes and military personnel. Alzheimers Res Ther 2014;6:4.

54 Gardner A, Iverson GL, McCrory P. Chronic traumatic encephalopathy in sport: a systematic review. Br J Sports Med 2014;48:84-90.

55 Manley G, Gardner AJ, Schneider KJ, et al. A systematic review of potential long-term effects of sport-related concussion. Br J Sports Med 2017:51:969-77. 